\title{
Hormone replacement therapy in general practice: a survey of doctors in the MRC's general practice research framework
}

\author{
H C Wilkes, T W Meade
}

\begin{abstract}
Objectives-To survey current prescribing practice for hormone replacement therapy among general practitioners and to elicit their views on the role of hormone replacement therapy in the prevention of osteoporosis and cardiovascular disease; to determine whether they would participate in randomised controlled trials to evaluate the long term beneficial and adverse effects of hormone replacement therapy.
\end{abstract}

Design-Postal questionnaires to general practitioners throughout the United Kingdom.

Participants -1268 general practitioners in the Medical Research Council's general practice research framework.

Results-1081 (85\%) doctors in 220 (95\%) practices responded. The doctors were currently prescribing hormone replacement therapy to an estimated $9 \%$ of their female patients aged 40 to 64 , and $55 \%$ of doctors were prescribing opposed hormone replacement therapy (oestrogen plus progestogen) to more patients than a year previously. Over half the doctors would consider prescribing hormone replacement therapy for prevention of osteoporosis $(670,62 \%)$ and cardiovascular disease $(611,57 \%)$ to asymptomatic women. Overall, $79 \%$ of the doctors (851) would definitely or probably consider entering women who have had a hysterectomy into a randomised controlled trial comparing unopposed (oestrogen only) hormone replacement therapy with opposed hormone replacement therapy; $49 \%$ (524) would enter patients with a uterus into such a trial. Among a subsample, $85 \%(180 / 210)$ would consider entering patients without menopausal symptoms into a trial comparing hormone replacement therapy with no treatment (unopposed in patients who have had a hysterectomy, opposed in those with a uterus).

Conclusion-There is considerable uncertainty among general practitioners as to the balance of beneficial and harmful effects of hormone replacement therapy in the long term, particularly relating to its use for prevention of osteoporosis and cardiovascular disease. Most of these doctors would be prepared to participate in randomised controlled trials to determine the long term effects of this increasingly widely used treatment.

\section{Introduction}

The increasing use of hormone replacement therapy for menopausal symptoms in the late 1970 s was slowed and then reversed with the finding that unopposed oestrogen may cause endometrial cancer. ${ }^{12}$ Usage has once again increased as a result of an increase in the use of opposed hormone replacement therapy. It is, however, possible that the addition of progestogen in opposed preparations might reduce the protective effect of unopposed oestrogen against cardiovascular disease because the progestogens most widely used in opposed preparations have potentially adverse effects on blood lipids. ${ }^{3}$ The likelihood that the proportion of postmenopausal women using hormone replacement therapy will increase considerably over the next decade emphasises the importance of establishing the relative benefits and hazards of different regimens as conclusively as possible. The survey described here sought to establish current practice in prescribing hormone replacement therapy among general practitioners in the Medical Research Council's general practice research framework, the factors that might influence their future prescribing patterns, and, in particular, their willingness or otherwise to take part in randomised trials.

\section{Methods}

The survey was carried out at the request of an MRC ad hoc group considering the use of hormone replacement therapy in osteoporosis. Initially, the ad hoc group was concerned mainly with the feasibility of trials to compare opposed and unopposed treatment. At a later stage general practitioners' views were also sought on a trial of hormone replacement therapy compared with no treatment in those not requiring hormone replacement therapy for menopausal symptoms.

The Medical Research Council's general practice research framework is a confederation of group general practices located throughout the United Kingdom and linked by an interest in research and collaboration in multicentre studies in a primary care setting. The research framework, coordinated by the MRC Epidemiology and Medical Care Unit, at present comprises 232 practices actively involved in a variety of projects. Practices have on average 5.4 partners and list sizes average about 11000 . This provides access to some 2.6 million people, about $4.5 \%$ of the British population. There is some underrepresentation of the metropolitan districts, but all the Office of Population Censuses and Surveys area aggregates have at least $2 \%$ of their populations represented. In each practice one partner, the contact doctor, liaises with the coordinating centre.

Questionnaires were posted in November 1989 to all general practitioners in the research framework. Nonresponders were sent up to three reminders. The questionnaire sought personal details and continued with questions on current prescribing practice for hormone replacement therapy. There followed a summary of the risks and benefits of the treatment, the uncertainty of these estimates being emphasised. A table showing estimated changes in mortality from hip fracture, endometrial cancer, breast cancer, ischaemic heart disease, and stroke due to both opposed and unopposed hormone replacement therapy was given. ${ }^{4}$ The doctors' views were sought on the use of hormone replacement therapy for prevention and their willingness to enter asymptomatic patients into randomised trials. A second questionnaire was sent only to the contact doctors in May 1990.

Associations between categorical variables were tested with the $\chi^{2}$ distribution. All doctors in the research framework were included in the survey. 
Results

CHARACTERISTICS OF DOCTORS

A total of 1267 doctors in 232 practices received the questionnaire and 1081 (85\%) doctors in $220(95 \%)$ practices replied. Table 1 shows that $809(75 \%)$ of the responders and $150(81 \%)$ of the non-responders were male $(\mathrm{p}=0 \cdot 11)$. Only $15(7 \%)$ of the senior partners and $21(10 \%)$ of the contact doctors were women. Nearly half $(47 \%)$ of the women worked part time.

\section{CURRENT PRESCRIBING PRACTICE}

Only two $(0 \cdot 2 \%$, one male, one female) respondents stated that they never prescribe hormone replacement therapy to perimenopausal or postmenopausal women for the relief of menopausal symptoms. Twenty four (9\%) female doctors and $117(15 \%)$ male doctors prescribe, if indicated, only at the specific request of the patient; the remainder prescribe with or without the patient's specific request. Also, 616 (76\%) male and $228(84 \%)$ female doctors prescribe to prevent osteoporosis. Table II lists other reasons for prescribing hormone replacement therapy: 154 (14\%) of doctors gave at least one other reason, notably for preventing cardiovascular disease ( $37 \%$ of reasons) and for women with an early menopause.

The 1023 (95\%) doctors who could give an estimate were treating an average of 24.6 women each (range 0-150), with female doctors (both full time and part time) treating an average of about five more women than their male colleagues. An estimated $9 \%$ of women aged 40-64 registered with these doctors are currently receiving hormone replacement therapy, but these figures remain to be validated by a search for recorded prescriptions in a sample of NHS notes. There is some

TABLE I-Characteristics of doctors responding to questionnaire on hormone replacement therapy

\begin{tabular}{|c|c|c|c|}
\hline & Men & Women & All \\
\hline No (\%) responding & $809(84 \cdot 4)$ & $272(88 \cdot 0)$ & $1081(85 \cdot 3)$ \\
\hline $\begin{array}{l}\text { No (\%) working part time }(<30 \\
\text { hours) }\end{array}$ & $29(3.6)$ & $127(46 \cdot 7)$ & $156(14 \cdot 4)$ \\
\hline No $(\%)$ who were "contact" doctors & $197(24 \cdot 4)$ & $20(7 \cdot 4)$ & $217(20 \cdot 1)$ \\
\hline No $(\%)$ who were senior partners & $199(24 \cdot 6)$ & $15(5 \cdot 5)$ & $214(19 \cdot 8)$ \\
\hline Median age (years) & $43 \cdot 2$ & $36 \cdot 5$ & $41 \cdot 6$ \\
\hline No (\%) not responding & $150(15 \cdot 6)$ & $37(12 \cdot 0)$ & $187(14 \cdot 7)$ \\
\hline
\end{tabular}

TABLE II - Reasons for prescribing hormone replacement therapy other than for menopausal symptoms or prevention of osteoporosis

\begin{tabular}{lcc}
\hline & $\begin{array}{c}\text { No of } \\
\text { doctors }\end{array}$ & $\begin{array}{c}\text { Percentage } \\
\text { of reasons }\end{array}$ \\
\hline Cardiovascular problems & 57 & $37 \cdot 0$ \\
Early menopause & 39 & $25 \cdot 3$ \\
Patient's request & 14 & $9 \cdot 1$ \\
Piychological problems (not necessarily related & 13 & $8 \cdot 4$ \\
to menopause) & 11 & $7 \cdot 1$ \\
Cycle control in perimenopause & 11 & $7 \cdot 1$ \\
Vaginal problems & 10 & $6 \cdot 5$ \\
Wellbeing or quality of life & 6 & $3 \cdot 9$ \\
Painful joints, aches, arthritis & 4 & $2 \cdot 6$ \\
Effects on skin or cosmetic reasons & 2 & $1 \cdot 3$ \\
Oestrogen deficiency & 3 & $1 \cdot 9$ \\
Other reasons & \\
\hline
\end{tabular}

Some doctors listed several of the above reasons for prescribing HRT.

TABLE III - Formulation prescribed and number of doctors who most frequently prescribe each type

\begin{tabular}{|c|c|c|c|c|}
\hline \multirow[b]{2}{*}{ Type of hormone replacement therapy } & \multicolumn{2}{|c|}{$\begin{array}{l}\text { No (\%) of doctors } \\
\text { who ever prescribe }\end{array}$} & \multicolumn{2}{|c|}{$\begin{array}{l}\text { No }(\%) \text { who most } \\
\text { frequently prescribe }\end{array}$} \\
\hline & $\begin{array}{c}\text { Male } \\
(\mathrm{n}=809)\end{array}$ & $\begin{array}{c}\text { Female } \\
(\mathrm{n}=272)\end{array}$ & $\begin{array}{c}\text { Male } \\
(\mathrm{n}=809)\end{array}$ & $\begin{array}{c}\text { Female } \\
(\mathrm{n}=272)\end{array}$ \\
\hline Oral oestrogen without progestogen & $617(76 \cdot 4)$ & $212(78 \cdot 2)$ & $34(4 \cdot 2)$ & $4(1 \cdot 5)$ \\
\hline Oral oestrogen with progestogen & $794(98 \cdot 3)$ & $268(98.9)$ & $674(83 \cdot 3)$ & $218(80 \cdot 1)$ \\
\hline Progestogen only & $168(20 \cdot 8)$ & $59(21 \cdot 8)$ & $4(0.5)$ & $1(0 \cdot 4)$ \\
\hline Implants only & $144(17 \cdot 8)$ & $44(16 \cdot 2)$ & $3(0 \cdot 4)$ & - \\
\hline Implants with oral progestogen & $77(9 \cdot 5)$ & $30(11 \cdot 1)$ & - & - \\
\hline Transdermal oestrogen only & $435(53 \cdot 8)$ & $179(66 \cdot 1)$ & $17(2 \cdot 1)$ & $4(1 \cdot 5)$ \\
\hline Transdermal oestrogen plus oral progestogen & $428(53 \cdot 0)$ & $179(66 \cdot 1)$ & $36(4 \cdot 4)$ & $19(7 \cdot 0)$ \\
\hline Vaginal creams & $630(78 \cdot 0)$ & $246(90 \cdot 8)$ & $36(4 \cdot 4)$ & $24(8 \cdot 8)$ \\
\hline Missing responses & $1(0 \cdot 1)$ & $1(0 \cdot 3)$ & $5(0 \cdot 6)$ & $2(0 \cdot 7)$ \\
\hline
\end{tabular}

TABLE IV-Brands of hormone replacement therapy specified as most frequently prescribed

\begin{tabular}{|c|c|c|c|}
\hline \multirow[b]{2}{*}{ Brand $\star$} & \multicolumn{3}{|c|}{ No (\%) of doctors } \\
\hline & Male & Female & All \\
\hline \multicolumn{4}{|c|}{ Oral oestrogen plus progestogen: } \\
\hline Prempak-C & $548(67 \cdot 7)$ & $207(76 \cdot 1)$ & $755(69 \cdot 8)$ \\
\hline Trisequens & $18(2 \cdot 2)$ & $4(1.5)$ & $22(2 \cdot 0)$ \\
\hline Cyclo-Progynova & $123(15 \cdot 2)$ & $20(7 \cdot 4)$ & $143(13 \cdot 2)$ \\
\hline Menophase & $11(1 \cdot 4)$ & $1(0.4)$ & $12(1 \cdot 1)$ \\
\hline \multicolumn{4}{|c|}{ Oral oestrogen without progestogen: } \\
\hline Harmogen & $4(0 \cdot 5)$ & & $4(0 \cdot 4)$ \\
\hline Progynova & $1(0 \cdot 1)$ & & $1(0 \cdot 1)$ \\
\hline Ethinyloestradiol & $6(0 \cdot 7)$ & & $6(0 \cdot 6)$ \\
\hline Premarin & $16(2 \cdot 0)$ & $1(0 \cdot 4)$ & $17(1 \cdot 6)$ \\
\hline \multicolumn{4}{|c|}{$\begin{array}{l}\text { Transdermal oestrogen plus oral } \\
\text { progestogen: }\end{array}$} \\
\hline Estrapak & $27(3 \cdot 3)$ & $19(7 \cdot 0)$ & $46(4 \cdot 3)$ \\
\hline Transdermal oestrogen only: & & & \\
\hline Estraderm & $31(3 \cdot 8)$ & $6(2 \cdot 2)$ & $37(3 \cdot 4)$ \\
\hline $\begin{array}{l}\text { Progesterone suppository: } \\
\text { Cyclogest }\end{array}$ & $1(0 \cdot 1)$ & & $1(0 \cdot 1)$ \\
\hline Vaginal cream: & & & \\
\hline Ortho Dienostrol & $14(1 \cdot 7)$ & $8(2 \cdot 9)$ & $22(2 \cdot 0)$ \\
\hline Ovestin & $1(0 \cdot 1)$ & $2(0 \cdot 7)$ & $3(0 \cdot 3)$ \\
\hline Missing & $8(1 \cdot 0)$ & $4(1 \cdot 5)$ & $12(1 \cdot 1)$ \\
\hline Total & 809 & 272 & 1081 \\
\hline
\end{tabular}

* Some doctors recorded a particular type as most frequently prescribed bu specified their most often used brand as of a different type.

evidence of regional variability in the proportion of women prescribed hormone replacement therapy, with the highest estimate of $10 \%$ in the south east compared with the lowest of 7\% (nearly a third lower) in Wales and in Yorkshire and Humberside.

Table III shows doctors' preferences for various forms of hormone replacement therapy. Almost all$1062(98 \%)$ - prescribe oral oestrogen plus progestogen to some women, with $892(83 \%)$ saying they most frequently prescribed this form. Female doctors were more likely to favour transdermal preparations and vaginal creams, $18 \%$ of women (48) and $11 \%$ of men (93) specifying these as most frequently prescribed $(p<0.02)$. Seven did not specify a most frequently used preparation. The second most frequently prescribed type of hormone replacement therapy was given by 1052 of the doctors. These doctors prescribed oral oestrogen without progestogen $(402,37 \%)$, oral oestrogen with progestogen $(123,11 \%)$, transdermal with or without oral progestogen $(296,27 \%)$, vaginal creams $(187,17 \%)$, and progestogen only or implants only $(44,4 \%) ; 29$ doctors did not specify a second most frequently used type. A total of 595 (55\%) doctors reported that they were prescribing more opposed hormone replacement therapy than one year ago; only $26(2 \%)$ said that they were prescribing less; $439(41 \%)$ reported no change; $14(1 \%)$ did not know; and seven did not respond.

Table IV shows the most frequently prescribed brands. The majority of doctors $(68 \%$ of men, $76 \%$ of women, $p=<0.02$ ) most frequently prescribe Prempak C. More male than female doctors most frequently prescribe Cyclo-Progynova (15\% v 7\%).

Table $\mathrm{V}$ shows the times at which doctors thought treatment could start. For the relief of menopausal symptoms $1033(96 \%)$ would initiate treatment before periods had completely stopped; 425 of these (41\%) would also initiate treatment up to five years and 318 (31\%) up to 10 years after menopause, and $242(23 \%)$ would consider starting treatment more than 10 years after periods had stopped. There was less agreement as to the appropriate time to start treatment with a view to preventing osteoporosis, with $31 \%$ considering that treatment should not start before periods had stopped.

Table VI shows the duration of treatment thought appropriate. Half the doctors considered six months to three years appropriate for menopausal symptoms. Ninety two (9\%) would consider treatment for more than 10 years, some doctors specifically mentioning vaginal creams in this context. Again, there was less 
TABLE $\mathrm{V}$-Time at which hormone replacement therapy should be started for relief of menopausal symptoms and for preventing osteoporosis

\begin{tabular}{|c|c|c|c|c|}
\hline & \multicolumn{4}{|c|}{ Reason for giving HRT } \\
\hline & \multicolumn{2}{|c|}{$\begin{array}{c}\text { Relief of } \\
\text { menopausal } \\
\text { symptoms }\end{array}$} & \multicolumn{2}{|c|}{$\begin{array}{l}\text { Preventing } \\
\text { osteoporosis }\end{array}$} \\
\hline & No & $\%$ & No & $\%$ \\
\hline Perimenopausal & 48 & $4 \cdot 5$ & 60 & $6 \cdot 4$ \\
\hline $\begin{array}{l}\text { Perimenopause to } 5 \text { years after } \\
\text { menopause }\end{array}$ & 425 & $39 \cdot 4$ & 241 & $25 \cdot 8$ \\
\hline $\begin{array}{l}\text { Perimenopause to } 5-10 \text { years after } \\
\text { menopause }\end{array}$ & 318 & $29 \cdot 5$ & 192 & $20 \cdot 6$ \\
\hline $\begin{array}{l}\text { Perimenopause to }>10 \text { years after } \\
\text { menopause }\end{array}$ & 242 & $22 \cdot 4$ & 153 & $16 \cdot 4$ \\
\hline Up to 5 years after menopause & 21 & 1.9 & 82 & 8.8 \\
\hline Up to 10 years after menopause & 13 & $1 \cdot 2$ & 92 & $9 \cdot 9$ \\
\hline Any time after menopause & 8 & 0.7 & 57 & $6 \cdot 1$ \\
\hline 5-10 Years after menopause & 1 & $0 \cdot 1$ & 18 & 1.9 \\
\hline$>5$ Years after menopause & & & 24 & $2 \cdot 6$ \\
\hline$>10$ Years after menopause & 1 & $0 \cdot 1$ & 14 & 1.5 \\
\hline Total responding & 1078 & 100 & 933 & 100 \\
\hline
\end{tabular}

TABLE VI-Duration of hormone replacement therapy considered appropriate for relief of menopausal symptoms and prevention of osteoporosis

\begin{tabular}{|c|c|c|c|c|}
\hline & \multicolumn{4}{|c|}{ Reason for giving HRT } \\
\hline & \multicolumn{2}{|c|}{$\begin{array}{c}\text { Relief of } \\
\text { menopausal } \\
\text { symptoms }\end{array}$} & \multicolumn{2}{|c|}{$\begin{array}{c}\text { Preventing } \\
\text { osteoporosis }\end{array}$} \\
\hline & No & $\%$ & No & $\%$ \\
\hline$<6$ Months & 25 & $2 \cdot 3$ & 1 & $0 \cdot 1$ \\
\hline$<6$ Months to 3 years & 75 & $7 \cdot 0$ & 1 & $0 \cdot 1$ \\
\hline$<6$ Months to 5 years & 56 & $5 \cdot 2$ & 5 & 0.5 \\
\hline$<6$ Months to 10 years & 33 & $3 \cdot 1$ & 4 & 0.4 \\
\hline$<6$ Months to $>10$ years & 44 & $4 \cdot 1$ & 9 & 0.9 \\
\hline 6 Months to 3 years & 545 & $50 \cdot 8$ & 59 & $6 \cdot 0$ \\
\hline 6 Months to 5 years & 67 & $6 \cdot 2$ & 20 & $2 \cdot 0$ \\
\hline 6 Months to 10 years & 42 & 3.9 & 31 & $3 \cdot 2$ \\
\hline 6 Months to $>10$ years & 23 & $2 \cdot 1$ & 22 & $2 \cdot 2$ \\
\hline 4 to 5 Years & 77 & $7 \cdot 2$ & 170 & $17 \cdot 4$ \\
\hline 4 to 10 Years & 8 & 0.7 & 75 & $7 \cdot 7$ \\
\hline 4 to $>10$ Years & 4 & $0 \cdot 4$ & 56 & $5 \cdot 7$ \\
\hline 6 to 10 Years & 53 & 4.9 & 267 & $27 \cdot 3$ \\
\hline 6 to $>10$ Years & 5 & 0.5 & 88 & 9.0 \\
\hline$>10$ Years & 16 & $1 \cdot 5$ & 171 & $17 \cdot 5$ \\
\hline Total responding & 1073 & 100 & 979 & 100 \\
\hline
\end{tabular}

agreement as to the appropriate duration for prevention of osteoporosis. Only $171(17 \%)$ thought treatment for less than three years was worth while, whereas $267(27 \%)$ thought between 6-10 years was optimal.

\section{DOCTORS'VIEWS ON RISKS AND BENEFITS}

A total of $611(57 \%)$ of the doctors would contemplate using hormone replacement therapy for routine prevention of cardiovascular disease in women with no contraindication, and $670(62 \%)$ would consider it for preventing osteoporosis. Both sexes responded similarly. Among those doctors who would not

TABLE VII-Doctors' willingness to enter women into randomised controlled trial of opposed versus unopposed hormone replacement therapy

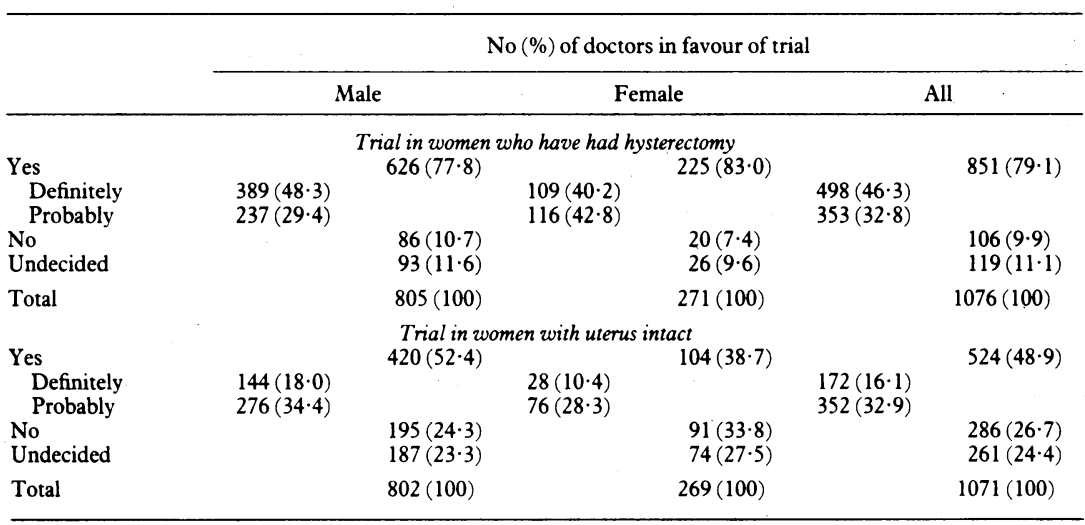

TABLE VIII-Doctors' willingness to enter patients into randomised controlled trial comparing hormone replacement therapy with placebo

\begin{tabular}{|c|c|c|c|c|}
\hline \multirow{4}{*}{$\begin{array}{l}\text { Yes } \\
\text { Definitely } \\
\text { Probably }\end{array}$} & \multicolumn{4}{|c|}{ No (\%) of doctors ${ }^{\star}$ willing to enter patients } \\
\hline & \multicolumn{2}{|c|}{ With hysterectomy } & \multicolumn{2}{|c|}{ With uterus } \\
\hline & & $181(86)$ & & $178(85)$ \\
\hline & $110(52)$ & & $96(46)$ & \\
\hline No & (דלנ) & $19(9)$ & & $19(9)$ \\
\hline Undecided & & $10(5)$ & & $13(6)$ \\
\hline
\end{tabular}

*Contact doctors only; 210 out of 215 replied.

contemplate routine use a strong feeling was that more research was needed to establish long term benefits and safety -184 (17\% of all doctors) gave this as a reason, accounting for $38 \%$ of the reasons stated.

When asked, "Do you consider that even a small increase in the risk of cancer, either of the breast or uterus, would preclude the use of unopposed oestrogens regardless of any benefit to cardiovascular disease?" male and female doctors tended to respond differently, with $199(25 \%)$ men and $105(39 \%)$ women answering "yes" $(\mathrm{p}<0.001)$. Overall, 477 . $(44 \%-47 \%$ of men and $36 \%$ of women) replied "no" and $300(28 \%)$ were undecided.

\section{SECOND QUESTIONNAIRE}

Of the 215 contact doctors questioned, 210 (98\%) responded. Asked if they ever prescribe opposed oestrogen to women who have had a hysterectomy, 37 (18\%) replied "yes," with seven (19\%) saying that this was less likely to cause breast problems, five (14\%) stating that some women respond better to opposed therapy, and the remainder giving a variety of reasons. Asked whether unopposed oestrogen was ever prescribed to women who had not undergone hysterectomy, 31 (15\%) replied "yes," with eight (26\%) saying that it was sometimes better tolerated and the rest giving other reasons.

DOCTORS' VIEWS ON RANDOMISED CONTROLLED TRIALS

Table VII shows that (from the first questionnaire) $46 \%$ of doctors (498) would definitely and $33 \%$ (353) would probably consider entering their patients into a randomised controlled trial to compare the long term balance of risks and benefits of opposed versus unopposed regimens in women who have had a hysterectomy; $11 \%$ (119) were undecided, and $10 \%$ (106) replied "no." Female doctors were less certain, with $40 \%$ (109) as compared with $48 \%$ (389) of men replying "definitely" $(p<0.03)$. In the case of women with a uterus, $16 \%$ of doctors (172) would definitely be prepared to undertake a trial, $33 \%$ (352) would probably do so, $27 \%$ (286) would not, and $24 \%$ (261) were undecided. Again, female doctors were less inclined to be in favour of this trial (39\% (104) compared with $52 \%(420)$ of male doctors, $p<0.001)$.

The second questionnaire asked if doctors would participate in a randomised controlled trial to compare hormone replacement therapy (opposed in women with a uterus, unopposed in women who have had a hysterectomy) with no treatment to establish the value of hormone replacement therapy in preventing osteoporosis and vascular disease in women initially free of menopausal symptoms. Table VIII gives the distribution of responses. For a trial in women who have had a hysterectomy, 110 doctors $(52 \%)$ would definitely participate and 71 (34\%) would probably participate. For women with a uterus these figures were $96(46 \%)$ and $82(39 \%)$ respectively.

\section{Discussion}

More or less by definition, doctors in practices in the MRC's general practice research framework tend to 
have a high level of interest in the unresolved questions of clinical benefits and hazards resulting from the growing use of treatments such as hormone replacement therapy. Because it is largely among doctors with these interests that the necessary research can be carried out, the self selection of practices into the research framework enhances the validity of the principal findings of this survey.

The current reported level of prescribing hormone replacement therapy-about $9 \%$ of women aged between 40 and 64 -is consistent with other estimates, though our figure remains to be validated. As expected, the use of opposed hormone replacement therapy is increasing. Although menopausal symptoms are the commonest reason for prescribing hormone replacement therapy, over half the doctors would contemplate its use for the prevention of osteoporosis or cardiovascular disease, or both. A recent survey indicates considerable interest among perimenopausal women in the use of hormone replacement therapy for preventing osteoporosis. ${ }^{5}$ Among doctors in the research framework who would not currently prescribe hormone replacement therapy for prevention, uncertainty about long term effects coupled with the need for further evidence was, the commonest reason.

Probably the most controversial issue is the place of unopposed oestrogen in treating women who have not undergone hysterectomy. The first questionnaire was mainly concerned with establishing the readiness or otherwise of doctors to participate in a randomised comparison of opposed and unopposed hormone replacement therapy in women who have not had a hysterectomy. The less controversial question of hormone replacement therapy (opposed or unopposed, depending on hysterectomy state) versus no hormone replacement therapy was posed to a subset of the doctors some months later. Thus the two trials were not presented as mutually exclusive alternatives.

Some doctors (a minority) for considered reasons prescribe unopposed oestrogen to women with a uterus, and half the doctors (more men than women) would be prepared to enter women who have not had a hysterectomy into a trial of opposed compared with unopposed hormone replacement therapy. A substantial number of doctors, however, consider that the risk of uterine cancer, however small, precludes the use of unopposed oestrogen in women who have not had a hysterectomy. The clinical and organisational implications of irregular bleeding, hyperplasia, or uterine cancer due to unopposed hormone replacement therapy should not be underestimated. At the same time, it is clear from the doctors' responses that categorical statements automatically ruling out the use (and, if so, any benefits) of unopposed hormone replacement therapy in women who have not had a hysterectomy are not justified. Much also depends on the fully informed views of patients themselves. Some doctors, though a minority, prescribe opposed oestrogen to some patients who have undergone hysterectomy. Some use of opposed treatment in women who have had a hysterectomy is also indicated by general clinical experience. Nearly $80 \%$ of doctors surveyed (no significant sex difference) would enter patients who have had a hysterectomy into a comparison of opposed and unopposed hormone replacement therapy.

There was a high level of readiness to participate in a trial of hormone replacement therapy (opposed in women with a uterus, unopposed in those who have had a hysterectomy) compared with no treatment in women without menopausal symptoms. A trial of this kind would establish the cardiovascular effects of giving hormone replacement therapy for long term preventive purposes, but any comparison of the cardiovascular effects of opposed and unopposed regimens would be indirect.

A recent review has concluded that trials are needed to resolve the uncertainties left by observational studies and by the unevaluated effects of opposed hormone replacement therapy. ${ }^{6}$ At the suggestion of the MRC group to whom the results of our survey were reported, proposals for feasibility studies of both the trials suggested (opposed versus unopposed hormone replacement therapy in women who have and have not had a hysterectomy; hormone replacement therapy compared with no hormone replacement therapy) were submitted to the Harrow Health District Ethics Committee, which approved both subject to careful monitoring and reporting of side effects.

We thank all the general practitioners in the framework for their cooperation in completing the questionnaire and in particular the contact doctors for coordinating the survey in their practices and for answering supplementary questions. We also thank Jackie Cooper for help with the analysis and Olive Fuller for meticulously ensuring such a high response rate.

1 Smith DC, Prentice R, Donovan JT, et al. Association of exogenous estroge and endometrial carcinoma. $N$ Engl f Med 1975;293:1164-7.

2 Persson I, Adami HO, Bergkvist L. Hormone replacement therapy and the risk of cancer in the breast and reproductive organs: a review of the epidemiological data. In: Drife JO, Studd JWW, eds. HRT and osteoporosis. London: Springer-Verlag, 1990:165-75.

3 Montgomery JC, Crook D Progestogens: symptomatic and metabolic side effects. In: Drife JO, Studd JWW eds. HRT and osteoporosis. London: Springer-Verlag 1990:197-208.

4 Ross RK, Pike MC, Henderson BE, et al. Stroke prevention and oestrogen replacement therapy. Lancet 1984;ii:505.

5 Draper J, Roland M. Perimenopausal women's views on taking hormone replacement therapy to prevent osteoporosis. BMF 1990;300:786-8.

6 Vandenbroucke JP. Postmenopausal oestrogen and cardioprotection. Lancet 1991;337:833-4.

(Accepted 18 April 1991)
Hart did not believe in the joint tuition of male and female students. Neither did he feel that women doctors could ever be very numerous or the equal of men, for the "physical weakness and sexual disadvantages of women for arduous and public pursuits" rendered most of them inherently unsuitable for medical work. Consequently: "If the profession of medicine were thrown open to women as freely as it is to men-as we have always thought it ought to be-it may reasonably be doubted whether more than a few would ever adopt it, and whether a very small proportion of that few would succeed in it." But, as even this passage indicates, he was far more liberal than many contemporary male doctors. Thus, a leading article in 1871 stated that "we desire, and we believe the profession at large desires, to see oppressive barriers removed from before ladies who wish to qualify for medical practice in obstetrics and diseases of women." "[W]e do not approve," said a later note, "of the exclusion of women from examination from medical or any other degrees, when they have gone through the required curricula of study, and are able to satisfy the same intellectual tests as men." Such opinions were far removed from those expressed by Hutchinson and Hart's other predecessors. They were also far in advance of those held by many medical men and institutions, including the BMA, in later years. In 1878, the year in which the Association voted to deny women membership, the Lancet could still maintain that the medical education of women violated "the laws of decency."

From Mirror of Medicine: $A$ History of the BMF by P W J Bartrip. Published jointly by the $B M \mathcal{F}$ and Oxford University Press; BMA members' price UK $£ 29$, overseas $£ 33$, including postage. Obtainable from the Publishing Manager, $B M \mathcal{F}$, PO Box 295, London WCIH 9TE. Non-members UK £35. Obtainable from OUP Distribution Services, Saxon Way West, Corby, Northamptonshire NN18 9ES. 